\title{
Evidence is sweet
}

\author{
Fiona Godlee editor in chief
}

The BMJ

The man most likely to be the UK's next prime minister has called for a review of what he calls "stealth sin taxes" (doi:10. 1136/bmj.14557). Boris Johnson says he is concerned about their disproportionate effect on poor people. He also wants to base the UK's tax policy “on clear evidence." If so, all of us who want to improve the public's health can rest easy: the accumulating evidence in favour of such taxes is becoming hard to counter.

First comes the evidence of the damage caused by excessive intake of sugar and of sugary drinks in particular. To the long and evidence based list itemised by Adam Briggs (doi:10.1136/ bmj.14616)—weight gain and obesity, diabetes, tooth decay, heart disease, and hypertension-we can now add cancer. A French study in over 100000 people, published this week in The $B M J$, finds a positive association between overall risk of cancer and intake of sugary drinks (doi:10.1136/bmj.12408).

Meanwhile the news has been full of reports that obesity causes more cases of some cancers than smoking does. On the list is colorectal cancer, rates of which are rising in younger adults, writes John Potter (doi:10.1136/bmj.14280). Increased sugar intake is among the causes, he says.

What then of the evidence that taxes work to reduce harmful intake? Setting aside the obvious and longstanding precedent of tobacco taxation, and the early reports from Scotland of the effectiveness of a minimum price of a unit of alcohol, there is now well documented evidence of the effect of taxes on sugary drinks from more than 30 countries that have implemented them.
As Adam Briggs writes, the cumulative evidence suggests that a $10 \%$ increase in price is broadly associated with a $10 \%$ fall in sales. This has been accompanied by a rise in sales of healthy alternatives such as water.

But England's approach to sugar taxes is different. In a world first, the soft drinks industry levy, in place since the spring, doesn't directly increase prices for consumers. Instead it levies taxes from importers and manufacturers to encourage them to remove added sugar from their products. Whether they decide to pass this additional cost on to consumers remains to be seen. The levy is being evaluated and must be allowed to run its course. A government green paper due imminently is expected to propose extending this levy to sugary milky drinks if the industry fails to act.

As for the regressive nature of "sin taxes," Briggs reports that behaviour change and health benefits are both greater among people in lower socioeconomic groups. Briggs suggests that, rather than dismantling an effective regressive tax, we should be finding ways to improve other progressive taxes.

But Johnson is an ideologically driven politician for whom the evidence is unlikely to hold much sway. More persuasive may be the growing public support for taxing unhealthy foods and drinks-55\% at the last count, reports Briggs, including 54\% of Conservative voters.

And there is always a chance, says Andy Cowper (doi:10.1136/ bmj.14554), that Jeremy Hunt might win the day. Some chance. Some choice. 